\title{
Study of a preoperative scoring system to predict difficult laparoscopic cholecystectomy
}

Received: 25 February, 2021

Accepted: 08 March, 2021

Published: 10 March, 2021

*Corresponding authors: Dr. Md Masleh Uddin Department of General Surgery, NMCH, Patna, India, Email:masleh006@gmail.com

https://www.peertechzpublications.com

Check for updates \section{Shakil Jawed ${ }^{4}$ \\ 1Department of General Surgery, AlIMS, Patna, India \\ ${ }^{2}$ Department of General Surgery, NMCH, Patna, India \\ ${ }^{3}$ Department of Gastrointestinal Surgery, AllMS, Patna, India \\ ${ }^{4}$ Department of Surgery, AlIMS, Patna, India}

Md Ashraf Ali ${ }^{1}$ Md Masleh Uddin ${ }^{2 \star}$, Md Nehal Ahmad $^{3}$ and

\begin{abstract}
Introduction: Laparoscopic Cholecystectomy (LC), one of the most commonly performed surgical procedures worldwide, is accepted as the gold standard in the treatment of symptomatic gallstones. Generally laparoscopic cholecystectomy has low incidence of morbidity, mortality and conversion rate to open surgery, but occasionally surgeons encountered difficulty while doing Laparoscopic cholecystectomy. Preoperative prediction of "difficult Laparoscopic cholecystectomy" improve the patient safety as well as useful in reducing the cost of therapy.
\end{abstract}

Aim: To study a scoring system based on various risk factors to preoperatively predict difficult Laparoscopic cholecystectomy.

Materials \& method: This study was conducted in Department of General surgery, Nalanda Medical College And Hospital Patna \& associated All India Institute of Medical Science Patna. A total of 105 patients were included in this study. There are total 15 score from history, clinical \& sonological findings. They were evaluated \& scored on the basis of scoring system. Score upto 5 is defined as easy, 6-10 as difficult and 11-15 as very difficult.

Result: Prediction comes true in $96.6 \%$ for easy, $87.8 \%$ for difficult $\& 60 \%$ for very difficult cases. Area under ROC curve is 0.96 and conversion rate is 3.8 in our study. Age $>50$ years, Male sex, $\mathrm{H}$ /o of hospitalisation due to acute cholecystitis, Palpable gallbladder, BMI >27.5, Abdominal scar, Thick walled GB (>4mm), and Pericholecystic collection were found to be significant predictive factors for difficult laparoscopic cholecystectomy.

Conclusion: With the help of preoperative prediction, high risk patients may be informed \& counseled before about probability of open conversion \& difficulty in laparoscopic cholecystectomy.

\section{Introduction}

Laparoscopic Cholecystectomy (LC), one of the most commonly performed surgical procedures worldwide, is accepted as the gold standard in the treatment of symptomatic gallstones [1]. Generally laparoscopic cholecystectomy has low incidence of morbidity, mortality and conversion rate to open surgery, but occasionally surgeons encountered difficulty while doing Laparoscopic cholecystectomy [2].

The risk factors which makes LC difficult includes old age, male sex, obesity, attack of acute cholecystitis, previous abdominal surgeries and certain ultrasonographic findings i.e. distended gall bladder, thickened gall bladder wall, pericholecystic fluid collection and impacted stone at neck of gall bladder etc.

In early years of laparoscopic cholecystectomy era, the rate of conversion to open procedure was $2-15 \%$. After years of learning and understanding the laparoscopic technique and increasing surgeon's experience, the conversion rate has been dropped to approximately $1-6 \%$ [3]. This conversion was neither a failure nor a complication, but an attempt to avoid complications. The identification of parameters predicting conversion would be useful to improve preoperative patient counseling, provide for better perioperative planning, 
optimize operating room efficiency, and to avoid laparoscopicassociated cost \& complications by performing an open operation when appropriate. Different scoring methodologies have been suggested from time to time using different criteria. This scoring system was developed by Randhawa \& Pujahari [4].

\section{Aims and objectives}

The aim of this study was to find out the validity of preoperative scoring system developed by Randhawa, et al. [4] to predict difficult laparoscopic cholecystectomy and chances of conversion from laparoscopic to open cholecystectomy.

\section{Materials and methods}

This study was conducted in Department of General Surgery, NMCH, Patna and associated AIIMS Patna between February 2019 to March 2020. A total 105 patients were included in this study after prior informed consent. Approval from the ethical committee of institution was taken before starting the study.

Study Design: Non randomized prospective study

Study Period: February 2019 to March 2020

Sample Size: 105 patients

Inclusion criteria: Patients with symptomatic gall stone disease admitted for laparoscopic cholecystectomy.

\section{Exclusion criteria}

- $\quad$ Patients unfit for anaesthesia

- Patients admitted with symptoms of acute cholecystitis

- Open conversion due to instruments failure

A preoperative score was given to each patient before surgery on the basis of history, clinical examinations \& ultrasonographic findings (Table 1). All surgeries were done by classical four port method by using $\mathrm{CO}_{2}$ pneumoperitoneum with 10mmHg pressure. Time were noted from first port insertion till last port closure. All intraoperative events were noted like adhesions at calot's triangle, duration of surgery, injury to artery/duct, bile/stone spillage etc. (Table 2).

\section{Statistical methods}

The collected data was compiled in a Microsoft Excel sheet, and subsequently suitable multivariate logistic regression analysis using SPSS 16.0 version was done accordingly with different appropriate statistical methods. A p value of $\leq 0.05$ was considered as statistically significant. Chi-square test/Fisher exact test was used to evaluate whether there was a significant association between preoperative and intraoperative outcome. Area under ROC was used to find the efficacy of preoperative score for predicting the intraoperative outcome.

\section{Results}

In our study 105 cases were included, of which 91(86.7\%)
Table 1: Scoring Factors.

\section{History}

Age

Sex

H/o Hospitalization

H/o Hospit

\begin{tabular}{c|c|}
\hline BMI & $<25$ \\
\hline Abdominal Scar & No \\
\hline
\end{tabular}

Palpable gall bladder No

0
Sonography

\section{Wall thickness \\ Pericholecystic collection}

Impacted stone

\begin{tabular}{|c|c|}
\hline Thin $<4 \mathrm{~mm}$ \\
No \\
No \\
\hline
\end{tabular}

Score

\begin{tabular}{l|l}
$\leq 50 \mathrm{Y}$ & 0 \\
\hline Female & 0
\end{tabular}

Clinical

0

0

0

0

0

Thick $>4 \mathrm{~mm}$
Yes
Yes

Score Max

Maximum Score

\begin{tabular}{l|l}
1 & 1
\end{tabular}

$1 \quad 1$

\begin{tabular}{l|l}
4 & 4
\end{tabular}

\begin{tabular}{|c|l|l|}
\hline $25-27.5$ & 1 & 2 \\
$>27.5$ & 2 & \\
\hline Infraumblical & 1 & 2 \\
Supraumblical & 2 & \\
\hline Yes & 1 & 1
\end{tabular}

2

2

1

$1 \quad 1$
Table 2: Surgery was labelled as easy/difficult/very difficult based on these findings.

\begin{tabular}{|c|c|c|}
\hline & Intra Operative difficult Criteria & Score \\
\hline Easy & Time taken $<60$ min, No bile spillage, No injury to duct / artery & $0-5$ \\
\hline Difficult & $\begin{array}{c}\text { Time taken } 60-120 \text { min, bile / stone spillage, Injury to duct, No } \\
\text { conversion }\end{array}$ & $6-10$ \\
\hline $\begin{array}{c}\text { Very } \\
\text { difficult }\end{array}$ & Time taken $>120$ min, conversion to open surgery & $11-15$ \\
\hline
\end{tabular}

were female and $14(13.3 \%)$ were male. Age of patients varied from range of $14-70$ years. The majority of patients were in the age group of 21 - 50 years. The mean age was 38.7 with standard deviation of 14.06 . Out of 105 patients, 57(54.3\%) had history of hospitalisation for acute attacks, of which 11 were male and 46 female. $30(28.6 \%)$ patients had BMI $<25$, 45(42.9\%) patients had BMI between $25-27.5$ \& 30(28.6\%) patients had BMI >27.5.

Multivariate analysis of intraoperative outcome with risk factors was carried out which predicted that Age $>50$ years $(\mathrm{P}<0.000)$, male sex $(\mathrm{P}<0.000)$, History of hospitalisation for acute cholecystitis $(\mathrm{P}<0.000), \mathrm{BMI}>27.5(\mathrm{P}<0.002)$, Abdominal scar $(\mathrm{P}<0.001)$, palpable GB $(\mathrm{P}<0.000)$, thickened GB wall $(\mathrm{P}<0.001)$ and pericholecystic collection $(\mathrm{P}<0.001)$ to be the statistically significant predictors of difficult laparoscopic cholecystectomy Table 3.

In our study for Difficult cases, score between 6-10, sensitivity $90 \%$, specificity $92.3 \%$, positive predictive value $87.8 \%$ and negative predictive value was $93.8 \%$.

For Easy cases, score between 0-5, sensitivity 93.4\%, specificity $95.5 \%$, PPV $96.6 \%$ and NPV was $91.3 \%$.

For Very difficult cases, score between $10-15$, sensitivity $75 \%$, specificity $98 \%$, PPV $60 \%$ and NPV was $99 \%$ Table 4 .

Area under ROC curve was 0.96 with $95 \%$ Confidence Interval $(0.931-0.996)$. Open conversion rate is $3.8 \%$. 
Table 3: Multivariate analysis of intraoperative outcome with risk factors.

\begin{tabular}{|c|c|c|c|c|c|}
\hline \multirow[t]{2}{*}{ Risk Factors } & \multirow[t]{2}{*}{ Level } & \multicolumn{3}{|c|}{ Intraoperative Outcome } & \multirow[t]{2}{*}{$P$ value } \\
\hline & & $\begin{array}{c}\text { Easy No. } \\
(\%)\end{array}$ & $\begin{array}{c}\text { Difficult No. } \\
(\%)\end{array}$ & $\begin{array}{c}\text { Very Difficult } \\
\text { No. (\%) }\end{array}$ & \\
\hline \multirow[t]{2}{*}{ Age } & $\leq 50$ years & $\begin{array}{c}65 \\
(76.47 \%)\end{array}$ & $19(22.35 \%)$ & $1(1.18 \%)$ & \multirow[t]{2}{*}{$<0.000$} \\
\hline & $>$ 50years & $12(60 \%)$ & $5(25 \%)$ & $3(15 \%)$ & \\
\hline \multirow{2}{*}{ Sex } & Female & $\begin{array}{c}59 \\
(64.84 \%)\end{array}$ & $30(32.97 \%)$ & $2(2.20 \%)$ & \multirow{2}{*}{$<0.000$} \\
\hline & Male & $\begin{array}{c}10 \\
(71.43 \%)\end{array}$ & $2(14.29 \%)$ & $2(14.29 \%)$ & \\
\hline \multirow{2}{*}{$\begin{array}{c}\text { History of } \\
\text { Hospitalisation }\end{array}$} & No & $\begin{array}{c}47 \\
(97.92 \%)\end{array}$ & $1(2.08 \%)$ & $0(0)$ & \multirow{2}{*}{$<0.000$} \\
\hline & Yes & $\begin{array}{c}14 \\
(24.56 \%)\end{array}$ & $39(68.42 \%)$ & $4(7.02 \%)$ & \\
\hline \multirow{3}{*}{ BMI } & $<25$ & $24(80 \%)$ & $6(20 \%)$ & $0(0)$ & \multirow{3}{*}{0.002} \\
\hline & $25.0-27.5$ & $\begin{array}{c}26 \\
(57.78 \%)\end{array}$ & $19(42.22 \%)$ & $0(0)$ & \\
\hline & $>27.5$ & $\begin{array}{c}11 \\
(36.67 \%)\end{array}$ & $15(50 \%)$ & $4(13.33 \%)$ & \\
\hline \multirow{3}{*}{ Abdominal scar } & No & $\begin{array}{c}46 \\
(68.66 \%)\end{array}$ & $21(31.34 \%)$ & $0(0)$ & \multirow{3}{*}{0.001} \\
\hline & Infraumbilical & $\begin{array}{c}15 \\
(40.54 \%)\end{array}$ & $19(51.35 \%)$ & $3(8.11 \%)$ & \\
\hline & Supraumbilical & $0(0)$ & $0(0)$ & $1(100 \%)$ & \\
\hline \multirow{2}{*}{$\begin{array}{l}\text { Palpable Gall } \\
\text { bladder }\end{array}$} & No & $\begin{array}{c}59 \\
(67.82 \%)\end{array}$ & $26(29.89 \%)$ & $2(2.30 \%)$ & \multirow[t]{2}{*}{$<0.000$} \\
\hline & Yes & $2(11.11 \%)$ & $14(77.78 \%)$ & $2(11.11 \%)$ & \\
\hline \multirow{2}{*}{$\begin{array}{l}\text { Gall bladder } \\
\text { wall thickness }\end{array}$} & $<4 \mathrm{~mm}$ & $\begin{array}{c}58 \\
(62.37 \%)\end{array}$ & $34(36.56 \%)$ & $1(1.08 \%)$ & \multirow[t]{2}{*}{0.001} \\
\hline & $\geq 4 \mathrm{~mm}$ & $3(25 \%)$ & $6(50 \%)$ & $3(25 \%)$ & \\
\hline \multirow{2}{*}{$\begin{array}{l}\text { Pericholecystic } \\
\text { collection }\end{array}$} & No & $\begin{array}{c}61 \\
(62.24 \%)\end{array}$ & $35(35.71 \%)$ & $2(2.04 \%)$ & \multirow[t]{2}{*}{0.001} \\
\hline & Yes & $0(0)$ & $5(71.43 \%)$ & $2(28.57 \%)$ & \\
\hline \multirow[b]{2}{*}{ Impacted stone } & No & $42(70 \%)$ & $17(28.33 \%)$ & $1(1.67 \%)$ & \multirow[b]{2}{*}{0.093} \\
\hline & Yes & $\begin{array}{c}19 \\
(42.22 \%)\end{array}$ & $23(51.11 \%)$ & $3(6.67 \%)$ & \\
\hline
\end{tabular}

Table 4: Correlation of pre-operative score and the outcome.

\begin{tabular}{|c|c|c|c|c|}
\hline Pre-op score & Easy (\%) & Difficult (\%) & Very Difficult (\%) & Total (\%) \\
\hline $0-5$ & $57(54.2 \%)$ & $2(1.9 \%)$ & $0(0)$ & $59(56.2 \%)$ \\
\hline $6-10$ & $4(3.8 \%)$ & $36(34.3 \%)$ & $1(0.95 \%)$ & $41(39.1 \%)$ \\
\hline $11-15$ & $0(0)$ & $2(1.9 \%)$ & $3(2.9 \%)$ & $5(4.8 \%)$ \\
\hline Total & $61(58.1 \%)$ & $40(38.1 \%)$ & $4(3.8 \%)$ & \\
\hline
\end{tabular}

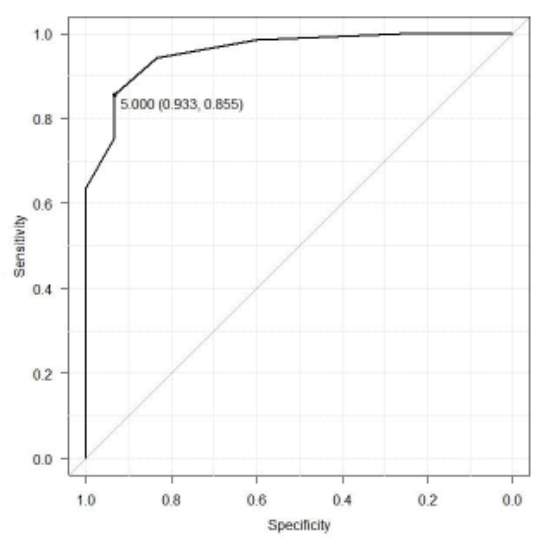

Area under RoC curve $=0.96$

ROC $=$ Receiving Operating Characteristics

\section{Discussion}

Since 1987, when Philipe Mouret first performed the Laparoscopic cholecystectomy [4], It has been widely performed throughout the world. In our institute (NMCH) also it is one of the most common operations performed. The main aim of our study is to detect preoperative predictors of difficult LC and the rate of conversion of laparoscopic to open cholecystectomy in our institute. Initially, the complication rate was high but with advancement in technologies and increase in the expertise, complication rate is very low, approximately $2.0-6.0 \%$ [5] and Conversion rate $2-15 \%$ [6].

In our study out of 105 cases 4 got converted to open cholecystectomy with conversion rate of $3.8 \%$. This conversion rate is comparable to several other studies like Randhawa, et al. [4] (2009) with conversion rate was $1.3 \%$, Gupta N, et al. [7] 4.3\%, Vikalp Gupta, et al. [8] 6\%. As the universal accepted range of conversion is $2-15 \%$, our finding is within the range.

The age of the patients varied from $14-70$ years. The majority of patients were in the age group of $21-50$ years. The mean age was 38.7 years with standard deviation of 14.06 . The conversion rate was highest in the age group of 51-60 years. Out of 15 patients, $9(60 \%)$ were difficult \& $2(13.3 \%)$ were very difficult which required open conversion. Where as in age group of 41-50 years, out of 24 cases $13(54.2 \%)$ were difficult $\& 1(4.2 \%)$ was very difficult which required open conversion. In our study, in multivariate logistic analysis age $>50$ years was found statistically significant predictor $(\mathrm{P}<0.000)$ of conversion.

Increasing age is associated with an increased probability of multiple attacks of cholecystitis and also increased frequency of upper abdominal surgeries. Therefore, there is increased incidence of fibrosis and adhesions in the hepatic hilum. Randhawa, et al. [4] found that age more than 50 years is associated with the same difficulties. In many studies, it was also found as a significant risk factor for difficult LC $[9,10]$. So it is observed that our finding is consistent with other studies $[4,7,11]$. Out of 105 patients, 14 were male and 91 were female. Male: Female ratio is 1: 6.5 which corroborates with the study of Ajay Anand, et al. [12] who also found female preponderance. Out of 14 male $10(71.4 \%)$ were difficult and $2(14.3 \%)$ were very difficult which got converted which accounts for $14.3 \%$ of male patients whereas out of 91 female 30 (32.9\%) were difficult and $2(2.2 \%)$ were very difficult which got converted which accounts for $2.2 \%$ of female patients. From this we can conclude that conversion rate is 6.5 times higher in male patients in this study which corroborates with the study of $\mathrm{H}$. J. J. van der Steeg, et al. (2011) and Volcan, et al. (2011) [13,14].

Difficulty in Male sex surgery reported in various studies $[10,15,16]$. Also high Conversion rate and significantly higher mortality has been reported in male patients [17]. In our study also it has been found as a significant factor $(\mathrm{P}<0.000)$.

There is a direct correlation between previous history of hospitalization due to acute attacks of cholecystitis and the difficulty level of laparoscopic cholecystectomy. Each attack 
of cholecystitis increases the gallbladder wall thickness and the gallbladder becomes scarred and fibrosed. It further increases the adhesions at the Calot's triangle and between gallbladder and fossa. In our study, out of 57 patients with H/o hospitalisation, $39(68.4 \%)$ were difficult \& 4(7\%) were very difficult which required open conversion. In our study, it was found to be a statistically significant factor for prediction of difficult LC $(\mathrm{P}<0.000)$. These cases were more time taking for calot's dissection and dissection of GB from liver bed ( $>60$ $\min )$.

Among clinical parameters, abdominal scar was also found to be significant predictor in this study. After prior upper or lower abdominal surgery there may be chances of adhesions between viscera or omentum and abdominal wall. Injury to these structures may occur during creation of pneumoperitoneum \& insertion of first port. Risk of conversion was higher due to these injuries. In our study 37 patients had infra-umbilical scar of which 19 (51.4\%) were difficult \& 3 $(8.1 \%)$ were very difficult which required open conversion and 1 of them had supra-umbilical scar which was very difficult \& required open conversion $(100 \%)$. This study is in agreement with A. J. Karayiann, et al. [18] who found that previous upper abdominal surgery was associated with an increased need for adhesiolysis, a prolonged operation time, a higher conversion rate , increased incidence of post-operative wound infection and a longer post-operative stay, but he consider previous abdominal surgery not a contraindication for laparoscopic cholecystectomy [19]. Similar to Fanaei SA, et al. (2009), our study also found Abdominal scar to be a significant predictive factors $(\mathrm{P}<0.001)$.

In our study BMI >27.5, out of 30 patients, 15 (50\%) were difficult \& $4(13.3 \%)$ were very difficult which required open conversion and it was found to be a significant factor $(\mathrm{P}<0.002)$. But in certain studies there was no difference in operative time, time to start general diet, length of hospitalization or complications in obese patients [20]. Stephen Wise unger et al. considered LC is safe and effective treatment for obese patients and it should be the procedure of choice for these patients, to avoid the complication of prolonged bed rest and wound infections, common in these patients.

Palpable gall bladder is a clinical finding seen in patients with distended gall bladder due to mucocele or empyema or adhesion of GB with omentum etc. There is difficulty in holding the fundus in distended GB, so aspiration of the contents of GB is often required. It is difficult, time consuming and chance of spillage of contents into the peritoneal cavity is always there. In few study by Gupta N, et al. [7], Randhawa, et al. [4] and Agrawal, et al. [11], palpable gallbladder has significants association with intraoperative difficulty. In our study 18 (17.1\%) out of 105 patients had palpable gall bladder, out of 18 , $14(77.8 \%)$ were difficult \& $2(11.1 \%)$ were very difficult which required open conversion and it has also been found to be a significant factor $(\mathrm{p}<0.000)$.

In this study, thickened gallbladder wall was present in $12(11.4 \%)$ out of 105 patients, $6(50 \%)$ out of 12 were difficult \& $3(25 \%)$ were very difficult which required open conversion and it was found to be significant factor for prediction $(\mathrm{P}<0.001)$ In this study, a good correlation between gallbladder wall thicknesses with difficulty and conversion to the open procedure was found which is in accordance with reports in other studies [21].

In our study, out of 105 patients, 45(42.9\%) had impacted stone and out of 45, 19(42.2\%) were easy, 23(51.1\%) were difficult and $3(6.7 \%)$ were very difficult which required open conversion. It was not found to be statistically significant ( $P$ $<0.093$ ) in our study but found to be statistically significant in various studies (Agrawal, et al. [11] Gupta N, et al. [7]). It is probably due to small sample size. Pericholecystic fluid is an ultrasonographic finding of acute cholecystitis and increases the difficulty in dissecting calot's triangle due to adhesion \& fibrosis. In our study 7 out of 105 patients had pericholecystic collection, $5(71.4 \%)$ out of 7 were difficult laparoscopic cholecystectomy \& 2 (28.6\%) were very difficult which required open conversion.

Pericholecystic collection was found to be a significant factor in our study $(P<0.001)$ concurrence with the study of Agrawal, et al. [11] In some studies it was not found as a significant predictive factor like Randhawa, et al. [4]. Gupta N, et al. [7].

Difficult dissection secondary to dense adhesions at calot's triangle was the most common cause for difficult laparoscopic cholecystectomy in this study. The other causes were contracted GB with dense adhesion, distended GB with omental adhesion, short \& dilated cystic duct leading to inability to apply clips, distended Hartmann's pouch, CBD injury, bleeding from gallbladder bed and tear of cystic artery, tear of gallbladder with spillage of stones and bile.

These various difficulties leading to operative time more than 90 minutes or conversion to open cholecystectomy were taken as difficult cases. The usual duration of surgery in expert hands is 45 to 50 minutes [22].

A preoperative scoring system was used in this study for prediction of difficult LC. Sensitivity of the scoring system for prediction of easy, difficult or very difficult LC are $93.4 \%, 90 \%$ $\& 75 \%$ respectively and specificity are $95.5 \%, 92.3 \%$ \& $98 \%$ respectively. Area under ROC curve is 0.96 . Prediction comes true in $96.6 \%$ for easy, $87.8 \%$ for difficult \& $60 \%$ for very difficult cases. Previous study done by Gupta N, et al. [7] on this scoring method had sensitivity and specificity of $95.7 \%$ and $73.7 \%$ respectively with positive predictive values for easy and difficult as $90 \%$ and $88 \%$, and area under ROC curve as 0.86 [7]. Another study done by Randhawa, et al. [4] had sensitivity and specificity of $75.00 \%$ and $90.24 \%$, respectively. Prediction came true in $88.8 \%$ for easy and $92 \%$ difficult cases and ROC curve was 0.82 .

So, in our study this preoperative scoring system was found to be more sensitive \& specific than previous studies. But positive predictive value for difficult cases was less as compared to the findings published by Randhawa, et al. [4] \& Gupta N, et al. [7]. This may be due to small sample size of our study as compared to Randhawa, et al. \& Gupta N, et al. 


\section{Conclusion}

From this study, we can conclude that preoperative scoring system is a good, reliable and useful method to predict difficulty in laparoscopic cholecystectomy in majority of cases and should be used as a screening procedure. It can help surgeons to get an idea of the potential difficulty to be faced in a particular patient. It can help in operative planning and the high risk patients may be informed accordingly.

Ethical approval: Ethical committee of Institution

\section{Author contribution}

Md Masleh Uddin: Manuscript writing, data collection, analysis

Md Ashraf Ali: Data collection, design, analysis

Md Nehal Ahmad: Data collection, analysis, design

Shakil Jawed: Design, data collection, analysis.

\section{References}

1. Mehraj A, Naqvi MA, Feroz SH, Rasheed H (2011) laparoscopic cholecystectomy:an audit of 500 patients. J Ayub Med Coll Abbottabad 23: 88-89. Link: http://bit.ly/38ISKsh

2. Al-Bahlooli HS, Al-Malahi A, Ghallab HN, Shuga'a Al-Dain A, Al Sabahi AA (2009) Conversion rate of laparoscopic to open cholecystectomy. Yemeni journal for medical sciences $1: 1-8$.

3. Al-Bahlooli HS, Al-Malahi A, Ghallab HN, Shuga'a Al-Dain A, Al Sabahi AA (2009) Conversion rate of laparoscopic to open cholecystectomy. Yemeni journal for medical sciences 1: 1-8

4. Randhawa JS, Pujahari AK (2009) Preoperative prediction of difficult lap chole: A scoring method. Indian J Surg 71: 198-201. Link: http://bit.ly/3eqXaBQ

5. Gadacz TR (2000) Update on laparoscopic cholecystectomy, including a clinical pathway. Surg Clin North Am 80: 1127-1145. Link: http://bit.ly/3rsQelm

6. Kama NA, Kologlu M, Dogsnay M, Reise E, Atli M, et al. (2001) A risk score for convertion from laparoscopic to open cholecystectomy. Am J Surg 181: 520525. Link: http://bit.ly/3qrGpJt

7. Gupta N, Ranjan G, Arora MP, Goswami B, Chaudhary P, et al. (2013) Validation of a scoring system to predict difficult laparoscopic cholecystectomy. Int J Surg 11: 1002-1006. Link: http://bit.ly/3kWqlJa

8. Gupta V (2017) Preoperative Prediction of Difficult Laparoscopic Cholecystectomy - A Scoring System. IJSR 13: 1041-1043.

9. Lee NW, Collins J, Britt R, Britt LD (2012) Evaluation of preoperative risk factors for converting laparoscopic to open cholecystectomy. Am Surg 78: 831e3. Link: http://bit.ly/3sWkrQk

10. Hussain A (2011) Difficult laparoscopic cholecystectomy: current evidence and strategies of management. Surg Laparosc Endosc Percutan Tech 21: 211217. Link: https://bit.ly/3rrcORJ

11. Agrawal N, Singh S, Khichy S (2015) Preoperative Prediction of Difficult Laparoscopic Cholecystectomy: A Scoring Method. Niger J Surg 21: 130-133. Link: http://bit.ly/30mctnl
12. Anand A, Pathania BS, Singh G (2007) Conversion In Laparoscopic Cholecystectomy: An Evaluation Study. 9. Link: Link: http://bit.ly/30o1zxi

13. Genc V, Sulaimanov M, Cipe G, llksen S, Erverdi N, et al. (2011) Hazinedaroglu. What necessitates the conversion to open cholecystectomy? A retrospective analysis of 5164 consecutive laparoscopic operations: Clinics 66: 417-420. Link: http://bit.ly/3uZitAF

14. van der Steeg HJ, Alexander S, Houterman S, Slooter GD, Roumen RM (2011) Risk factors for conversion during laparoscopic cholecystectomy experiences from a general teaching hospital. Scand J Surg 100: 169-173. Link: http://bit.ly/3cqwDSX

15. Nachnani J, Supe A (2005) Pre-operative prediction of difficult laparoscopic cholecystectomy using clinical and ultrasonographic parameters. Indian J Gastroenterol 24: 16-18. Link: http://bit.ly/3qr3FHo

16. Lein HH, Huang CS (2002) Male gender: risk factor for severe symptomatic cholelithiasis. World J Surg 26: 598e601. Link: http://bit.ly/3qrFIFt

17. Bouarfa L, Schneider A, Feussner H, Navab N, Lemke HU, et al. (2011) Prediction of intraoperative complexity from preoperative patient data for laparoscopic cholecystectomy. Artif Intell Med 52: 169-176. Link: http://bit.ly/30pIWZQ

18. Karayiann AJ, polychronidi A, perent S, Botaitis S, Simopoulos C (2004) Laparoscopic cholecystectomy in patient with previous upper or lower in surgery. Surg Endosc 18: 1097-1101. Link: http://bit.ly/3sYiliL

19. Akyurak N, Salman B, Irkorucu O, Tascilar O, Yuksel O, et al. (2005) Laparoscopic cholecystectomy in patient with previous abdominal surgery. JSLS 9: 178-183. Link: http://bit.ly/3qlgwLa

20. Simopoulos C, Polychronidis A, Botaitis S, Perente S, Pitiakoudis M (2005) Laparoscopic cholecystectomy in obese patients. Obes Surg 15: 243-246. Link: http://bit.ly/3rrbRsD

21. Schrenk $P$, Woisetschlager $R$, Rieger $R$, Wayand WU (1998) A diagnostic score to predict the difficulty of a laparoscopic cholecystectomy from preoperative variables. Surg Endosc 12: 148-150. Link: http://bit.ly/3t53jll

22. Alponat A, Kum CK, Koh BC, Rajnakova A, Goh PM (1997) Predictive factors for conversion of laparoscopic cholecystectomy. World Jr Surg 21: 629-633. Link: http://bit.ly/3qkvBwA

\section{Discover a bigger Impact and Visibility of your article publication with}

\section{Peertechz Publications}

\section{Highlights}

* Signatory publisher of ORCID

* Signatory Publisher of DORA (San Francisco Declaration on Research Assessment)

* Articles archived in worlds' renowned service providers such as Portico, CNKI, AGRIS, TDNet, Base (Bielefeld University Library), CrossRef, Scilit, J-Gate etc.

* Journals indexed in ICMJE, SHERPA/ROMEO, Google Scholar etc.

* OAI-PMH (Open Archives Initiative Protocol for Metadata Harvesting)

* Dedicated Editorial Board for every journal

* Accurate and rapid peer-review process

* Increased citations of published articles through promotions

* Reduced timeline for article publication

Submit your articles and experience a new surge in publication services (https://www.peertechz.com/submission).

Peertechz journals wishes everlasting success in your every endeavours.

Copyright: ๑ 2021 Ali MA, et al. This is an open-access article distributed under the terms of the Creative Commons Attribution License, which permits unrestricted use, distribution, and reproduction in any medium, provided the original author and source are credited. 